\title{
El profesor José María López Piñero. Reflexiones desde el recuerdo
}

Josep Bernabeu-Mestre $(*)$

$(*)$ Historia de la Ciencia. Universitat d'Alacant

Dynamis

[0211-9536] 2011; 31 (1): 237-240

Cuando recibí la noticia del fallecimiento del profesor José María López Piñero en agosto del 2010, me encontraba preparando la asignatura de Introducción a las Ciencias de la Salud que, desde el curso 2010-2011, se imparte a los alumnos del primer curso del Grado de Nutrición Humana y Dietética en la Universidad de Alicante. Entre los materiales que tenía encima de la mesa estaban muchos de sus textos docentes, todos ellos de gran utilidad para poder preparar los contenidos de una asignatura que pretende trasladar a los alumnos una panorámica del campo científico en el que se van a socializar, y que intenta ayudar a entender el presente desde el conocimiento del pasado. Esta sería una de las primeras reflexiones que me gustaría trasladar sobre la obra del profesor López Piñero: su contribución a la mejora de la docencia y al aprendizaje de las ciencias de la salud.

Cuando comencé mi licenciatura de medicina en el curso 1974-1975 en la Facultad de Valencia, el plan de estudios no contemplaba la asignatura de Introducción a la Medicina que se había impartido en años anteriores. Mi primer contacto con el profesor López Piñero llegaría con la Historia de la Medicina en cuarto curso. Quienes ejercíamos de alumnos internos en alguna de las cátedras de Patología Médica, al tener que estar en las salas con los enfermos, no solíamos asistir a las clases de aquellas «asignaturas menores» que se impartían en los horarios de media mañana. Con la Historia de la Medicina hice una excepción y asistí a todas ellas. Desde el primer día quedé sorprendido por la capacidad de los profesores López Piñero y Francesc Bujosa para hacer atractiva la asignatura, y sobre todo para llevar sus reflexiones a los problemas y los retos que interesaban y preocupaban a la medicina de aquellos años. Fue entonces cuando creo que entendí 
por primera vez la condición social de las ciencias de la salud. Su forma de explicar la disciplina permitía desarrollar esquemas interpretativos de la ciencia y de la práctica médica analizados con todas las implicaciones sociales. Resulta obligado recordar la contribución del profesor López Piñero al proceso de ampliación de la base disciplinar de la Historia de la Medicina, mediante el dialogo con la Historia de la Ciencia, la Historia Social, la Antropología de la Salud, la Sociología de la Salud, o la Demografía y la Epidemiología Históricas.

Aunque finalmente decidí opositar a una plaza de alumno interno de Psiquiatría, el interés que me había despertado la Historia de la Medicina no decayó. Recuerdo aquella tarde del mes de junio en la que junto a Carlos Benito Amat, compañero de promoción y en la actualidad cualificado documentalista, nos acercamos a la entonces Cátedra de Historia de la Medicina y Documentación Médica de la Facultad de Valencia, para hablar con el profesor López Piñero sobre la posibilidad de dedicarnos a la Historia de la Medicina y la Documentación. Su recomendación fue que no nos precipitásemos y nos animó a explorar otras posibilidades. Continúe con la Psiquiatría pero acabé por volver a la Cátedra de Historia de la Medicina y me decanté por realizar la tesis de licenciatura sobre un tema de demografía histórica de la mano del profesor Bujosa.

Con el profesor López Piñero volví a coincidir en el curso 1982-1983, cuando tuve la suerte de asistir como alumno a su curso de doctorado sobre Historia de la Ciencia en España. Siempre recordaré su magisterio en las sesiones de análisis de textos y su capacidad para exponer las hipótesis, los datos y las ideas defendidas por los autores de los textos seleccionados, además de su habilidad para contextualizar dicho análisis. Esta sería otra de las reflexiones sobre el profesor López Piñero, que me gustaría compartir, su destreza en el manejo de la heurística y su acierto en la elección de los criterios que le permitían buscar y seleccionar las fuentes de información. El programa de trabajo que dejó diseñado en la malograda colección de «Textos clásicos españoles de la salud pública» que empezó a publicar el Ministerio de Sanidad en 1983, es uno de los ejemplos más destacados de sus contribuciones, y su recuperación representaría un merecido homenaje y reconocimiento a su condición de dinamizador e innovador en el campo de la historiografía médica española.

Junto a aquellas experiencias como alumno, conté con sus acertados consejos y comentarios, tanto en el diseño como en la elaboración de la tesis doctoral que llevé a cabo, bajo la dirección del profesor Emilio Balaguer, 
sobre la dialéctica entre tradición y renovación científica en la medicina española del período moderno. Las conversaciones que mantuvimos me ofrecieron la oportunidad de aprovechar esa ayuda inestimable que nos aportan los investigadores sénior a los más noveles. Sus contribuciones al estudio de la actividad científica y técnica en la España moderna y contemporánea, y la revisión que realizó de los esquemas historiográficos que se venían utilizando, han resultado fundamentales para el avance del conocimiento histórico de toda aquella realidad.

Con el profesor López Piñero también pude colaborar en alguna de las obras colectivas que dirigió, así como en el único trabajo que pudimos compartir con motivo de la celebración en Barcelona, en abril de 1987, del Primer Coloquio Hispano-Luso-Italiano de Demografía Histórica. El profesor López Piñero había quedado encargado de organizar junto con el profesor Lorenzo Del Panta, una destacada autoridad en el campo de la demografía histórica italiana y especialista en el análisis de las crisis de mortalidad, una sesión sobre «Los condicionantes de la mortalidad entre 1800 y 1930: higiene, salud y medio ambiente». Las limitaciones que acompañaron la trayectoria académica del profesor López Piñero no le permitieron asistir al Coloquio. Me encontré ante el reto de sustituirlo y la oportunidad de poder trabajar conjuntamente la ponencia-relación que pude defender, y que finalmente fue publicada en un número conjunto de los boletines de demografía histórica de la Asociación de Demografía Histórica y de la Società Italiana di Demografia Storica.

El planteamiento de los profesores López Piñero y Del Panta entroncaba de pleno con el debate sobre las causas que habían acompañado el descenso de la mortalidad durante la transición demográfica, y en cierto modo, adelantaban muchos de los elementos que han acabado por redefinir la teoría de la transición epidemiológica en la conocida como transición sanitaria y de riesgos. Frente a la atención que se había prestado a las «epidemias» en sentido clásico, y a la cronología, intensidad y extensión de las crisis de mortalidad, se destacaba la poca atención que se había mostrado a la llamada «mortalidad ordinaria» y el abordaje interdisciplinar de sus determinantes. En la ponencia que tuvimos ocasión de preparar, el profesor López Piñero proponía todo un programa de investigación sobre los problemas semánticos de las causas de defunción, y las dificultades que entraña el análisis de las expresiones diagnósticas que informan de las causas de muerte. Muchas de aquellas propuestas, en parte materializadas en proyectos previos dirigidos por él, se fueron concretando en investigaciones y seminarios desarrollados 
en las últimas décadas desde los grupos de investigación de Historia de la Medicina de las universidades de Valencia y Alicante, y han representado un referente para los estudios de epidemiología histórica.

El recuerdo del Profesor López Piñero suscita reflexiones. Nos gustaría acabar con una última consideración, que creemos está también implícita en su obra y su trayectoria. Nos estamos refiriendo a la necesidad que tienen la Historia de la Medicina y de la Ciencia de seguir abriendo fronteras a través del dialogo interdisciplinar y la incorporación crítica de las nuevas tendencias y corrientes historiográficas. 